\title{
Análise exploratória da eficiência produtiva dos portos brasileiros
}

\author{
Francisco Gildemir Ferreira da Silva ${ }^{1}$, Francisco Giusepe Donato Martins ${ }^{2}$, \\ Carlos Henrique Rocha ${ }^{3}$ e Carlos Eduardo Freire Araújo ${ }^{4}$
}

\begin{abstract}
Resumo: Este trabalho explorou e comparou a eficiência produtiva dos portos brasileiros em um momento específico e de forma intertemporal, a fim de avaliar se a administração portuária influi na eficiência portuária. Para tanto, utilizou-se da técnica DEA e do índice Malmquist. Propôs-se a adoção do modelo DEA baseado em teste de hipótese para determinação de retornos de escala como inovação metodológica. Os portos analisados apresentaram variâncias temporais na eficiência, sem, contudo, apresentar variações tecnológicas. Recomenda-se prosseguir o estudo com um painel de dados com mais variáveis.

Palavras-chave: portos; análise de eficiência; economia de transportes.
\end{abstract}

\begin{abstract}
This paper explored and compared the productive efficiency of Brazilian ports at a specific time and in an intertemporal manner in order to assess whether the port administration influences port efficiency. This assessment was carried out using DEA and Malmquist index. The use of an hypothesis-test based DEA model for determining returns to scale was proposed as a methodological innovation for this analysis. The ports analyzed presented temporal variance efficiency, but without technological variances. Further research using a data set with more variable is recommended. (Abstract translation by the editorial team)
\end{abstract}

Keywords: ports; efficiency analysis; transport economy.

\section{INTRODUÇÃO}

O Brasil criou, em 1990, o Programa Nacional de Desestatização (PND), por meio da Lei 8.031, a qual sofreu diversas alterações que vieram a originar a Lei 9.491/1997. Este normativo prescreve várias modalidades operacionais para realizar esse programa, destacam-se a concessão, permissão e autorização de serviços públicos. Sequencialmente, foi editada a Lei 8.630/1993, denominada de Lei de Modernização dos Portos, que atribui à União o direito de explorar o porto organizado, diretamente ou mediante concessão sempre precedida de licitação. Assegura, também, a quem interessar o direito de construir, reformar, ampliar, melhorar, arrendar e explorar instalação portuária, mediante: (a) contrato de arrendamento; e (b) autorização, cada qual para casos específicos descritos em Lei.

Além desse arcabouço, recentemente, foi editado o Decreto 6.620/2008 onde políticas e diretrizes foram estabelecidas para o desenvolvimento e o fomento do setor de portos e terminais portuários de competência da Secretaria Especial de Portos da Presidência da República (SEP/PR), bem como foram disciplinados a concessão de portos, o arrendamento e a autorização de instalações portuárias marítimas. As diretrizes conduzem, entre outras coisas, à busca de melhoria do desempenho operacional do setor portuário marítimo, que, por sua vez, traz à tona o tema sobre efici-

\footnotetext{
${ }^{1}$ Francisco Gildemir Ferreira da Silva, Pós-graduação em Economia, Universidade Federal do Ceará, Fortaleza, CE, Brasil. (e-mail: gildemir@gmail.com).

${ }^{2}$ Francisco Giusepe Donato Martins, Programa de Pós-Graduação em Transportes, Universidade de Brasília, Brasília, DF, Brasil. (e-mail: franciscogd@tcu.gov.br).

${ }^{3}$ Carlos Henrique Rocha, Programa de Pós-Graduação em Transportes, Universidade de Brasília, Brasília, DF, Brasil. (e-mail: chrocha@unb.br).

${ }^{4}$ Carlos Eduardo Freire Araújo, Programa de Pós-Graduação em Transportes, Universidade de Brasília, Brasília, DF, Brasil. (e-mail: eduardo@mkmbr.com.br).
}

Manuscrito recebido em 12/5/2010 e aprovado para publicação em 8/3/2011. Este artigo é parte de TRANSPORTES v.19, n.1, 2011. ISSN: 2237-1346 (online). ência produtiva no âmbito de indústrias reguladas.

Esse tema tem sido extensivamente discutido na literatura e abordado de maneira vasta e diversa em termos de metodologia adotada para análise da eficiência produtiva (Coelli et al., 1997). Especificamente, no âmbito do setor portuário, destaca-se o de Rios et al. (2004) sobre eficiência de portos brasileiros na operação em terminais de contêineres, bem como estudos comparativos entre os portos e sobre a efetividade da Lei 8.630/1993 (Castro e Lamy, 1992; Lima e Velasco, 1997; GEIPOT, 1998 e 2001; CNT, 2006; Fontes e Mello, 2006; e Souza Júnior, 2007). Apesar da ampla literatura sobre aplicação de técnicas para mensurar a eficiência, há poucos estudos sobre análise de eficiência produtiva sobre portos brasileiros.

O objetivo deste trabalho é analisar de forma exploratória e comparativa a eficiência produtiva dos portos brasileiros, aplicando a técnica DEA (Data Envelopment Analysis) e o índice Malmquist para verificar intertemporalmente o grau de eficiência produtiva pós Lei 8.630/1993, de modo a avaliar se a administração portuária influi na eficiência portuária. Para tanto, a presente pesquisa foi dividida em cinco seções, considerando-se esta introdução. A segunda seção trata de breve resumo das técnicas quantitativas e índices intertemporais para mensurar eficiência à luz da teoria econômica. A terceira seção descreve as principais características do setor portuário brasileiro, à luz do arcabouço jurídico vigente. A quarta seção apresenta a metodologia, aplicação e resultados adotados e as diferenças das abordagens feitas em outros trabalhos. Por fim, na última seção, são apresentadas as considerações finais.

\section{BACKGROUND TEÓRICO}

Nesta seção, discutem-se as ferramentas utilizados na avaliação de eficiência produtiva, à luz da teoria econômica da produção. 


\subsection{Conceitos inerentes à eficiência econômica}

A avaliação da eficiência econômica, com vertentes alocatica, distributiva e produtiva, tem se concentrado em aspectos estáticos, o que conduziu à busca de análise mais ampla a partir do conceito de eficiência dinâmica, que englobe investimentos e capacidade de inovação tecnológica e, não somente, as condições de decurso temporal ou o critério de eficiência alocativa de Pareto de escolha ótima entre alocações de recursos limitados a tecnologias e instituições dadas. Nesse escopo, surge o termo produtividade que apresenta, conforme Coelli et al. (1997), várias nuances na sua forma de mensuração, o que requer, portanto, descrever definições comumente utilizadas, tais como:produtividade; eficiência produtiva ou técnica; eficiência alocativa; mudanças técnicas; economias de escala; produtividade total do fatores (PTF); fronteira de produção; e conjunto factível de produção.

A produtividade é definida como a relação entre o produzido e os insumos necessários para a produção. No caso de múltiplos insumos e produtos o conceito produtividade equivale a PTF. A fronteira de produção representa a produção máxima para cada nível de insumo e reflete o estado da tecnologia na indústria. A empresa é tecnicamente eficiente se está na fronteira de produção, sendo ineficiente se estiver abaixo da curva. Todos os pontos abaixo da curva são factíveis, porque dado uma combinação de insumos pode-se produzir, contudo, acima da curva não se pode produzir com o insumo relativo, pois ultrapassaria a fronteira de produção da indústria.

A passagem do tempo implica mudança ou deslocamento da fronteira de produção com ampliação ou redução do conjunto de produção. Neste sentido, podem-se distinguir duas eficiências: a momentânea e a decorrente de mudanças técnicas. Chamaremos a primeira de eficiência parcial e a segunda de temporal. Conforme Coelli et al. (1997), o crescimento em produtividade é consequência das melhorias em eficiência, via mudanças técnicas ou economias de escala, podendo ainda ser resultado de uma combinação desses fatores. Por fim, Farrell (1957) indica que a eficiência técnica reflete a habilidade das firmas de obter produção máxima com os insumos dados, enquanto que a eficiência alocativa reflete a habilidade das firmas de utilizar os insumos em proporções ótimas, no sentido de Pareto, dados seus preços.

\subsection{O ferramental de análise de eficiência produtiva}

As técnicas utilizadas para medir eficiência produtiva devem mimetizar o comportamento descrito na seção anterior. Dos métodos computacionais, podem-se destacar: modelos econométricos de funções de produção; índices de PTF; análise envoltória de dados (DEA); e fronteira estocástica. Apresentam-se, a seguir, essas técnicas, enfatizando o método DEA.

\subsubsection{Modelos econométricos e índices de PTF}

$\mathrm{Na}$ abordagem econométrica, estimam-se parâmetros que consigam aproximar uma amostra a uma função matemática e um componente aleatório e cujos parâmetros sejam não viesado e eficiente do ponto de vista estatístico (Gujarati, 2000; e Pindyck e Rubinfield, 2004). Constitui, assim, um método paramétrico. A função a ser estimada é definida com base na teoria econômica da produção. Em regra, utiliza-se uma função Cobb-Douglas, mas existem funções mais gerais, tipo: CES e Translog. A vantagem das estimativas econométricas é a possibilidade de testar o comportamento dos parâmetros podendo obter respostas relativas aos ganhos de escala (identificação e nível), à relevância de insumos na produção, às mudanças tecnológicas, entre outras. A desvantagem é a necessidade de ter amostras grandes e com mínimo de erros de mensuração, pois, como o método é paramétrico, deve-se testar a validade estatística dos parâmetros.

O PTF é representado por um número índice, sendo os índices Tornqvist e quantitativo de Tornqvist os mais utilizados. Coelli et al. (1997) apontam a econometria como método para mensurar o PTF. Ainda há a possibilidade de utilizar índices de PTF multilaterais que são utilizados para comparar produtividade relativa. Tem-se ainda o índice Malmquist (1953), conforme Equações 1, 2 e 3, que é aplicado, consoante Färe et al. (1994), para medir a variação de eficiência técnica e quão distante a produção observada está do máximo produto potencial entre os períodos $t$ e $t+1$. O índice Malmquist será utilizado neste artigo para medir a eficiência intertemporal e a variância tecnológica.

$$
\begin{gathered}
M_{0}\left(x^{t+1}, y^{t+1}, x^{t}, y^{t}\right)=\frac{D_{0}^{t+1}\left(x^{t+1}, y^{t+1}\right)}{D_{0}^{t}\left(x^{t}, y^{t}\right)} \times \\
\times\left[\frac{D_{0}^{t}\left(x^{t+1}, y^{t+1}\right)}{D_{0}^{t+1}\left(x^{t+1}, y^{t+1}\right)} \times \frac{D_{0}^{t}\left(x^{t}, y^{t}\right)}{D_{0}^{t+1}\left(x^{t}, y^{t}\right)}\right]^{1 / 2} \\
\text { Variância_da_eficiência }=\frac{D_{0}^{t+1}\left(x^{t+1}, y^{t+1}\right)}{D_{0}^{t}\left(x^{t}, y^{t}\right)} \\
\text { Variância_Tecnológica }=\left[\frac{D_{0}^{t}\left(x^{t+1}, y^{t+1}\right)}{D_{0}^{t+1}\left(x^{t+1}, y^{t+1}\right)} \times\right. \\
\left.\times \frac{D_{0}^{t}\left(x^{t}, y^{t}\right)}{D_{0}^{t+1}\left(x^{t}, y^{t}\right)}\right]^{1 / 2}
\end{gathered}
$$

em que,

$M$ : índice Malmquist; e

$D$ : função que mensure distância.

Os sobrescritos referem-se ao tempo. Pode-se utilizar a técnica DEA e a fronteira estocástica para encontrar o índice Malmquist, sendo essas duas técnicas explicadas na próxima subseção.

\subsubsection{Fronteira estocástica e DEA}

A fronteira estocástica e o DEA podem ser utilizados como método alternativo de estimar funções de fronteira. O primeiro é um método paramétrico proposto por Agner et al. (1977) e Meeusen e Van den Broeck (1977), concomitantemente, e consiste em uma regressão onde o valor da produção é limitada pela variável aleatória $(\exp (x i+v i))$. A expressão $\exp (x i)$ é a própria função de produção e vi é um termo idiossincrático com média 0 e variância $\sigma$.

$\mathrm{Na}$ fronteira estocástica, estima-se a equação com os termos aleatórios via máxima verossimilhança e testam-se as hipóteses relativas à estimação. Havendo, de acordo com Greene (1990), problema de definição a priori da distribuição do componente do erro que serve para relatar a eficiência da função produção apreciada com o erro da real (Ui).

Além da estimativa de fronteira estocástica, tem-se a 
análise envoltória de dados, técnica a ser utilizada neste artigo, que é uma técnica de avaliação da eficiência relativa entre unidades produtivas que executam as mesmas tarefas e possuem objetivos semelhantes, utilizando múltiplos produtos e múltiplos insumos, conforme Charnes et al. (1994). Belloni (2000), resumidamente, diz que uma análise DEA fornece três resultados básicos, que são: a identificação de um conjunto de unidades eficientes (que determinam a fronteira de eficiência); a medida de ineficiência para cada unidade que não está sobre a fronteira (uma distância à fronteira que representa a potencialidade de crescimento da produtividade); as taxas de substituição (pesos) que determinam cada região da fronteira de eficiência e caracterizam as relações de valor que sustentam a classificação dessa região como eficiente.

Gonçalez e Trujilo (2008), Lin e Tseng (2005) e Wang et al. (2002) apontam vários estudos em eficiência em portos com técnicas paramétricas e não paramétricas. O DEA teve seu primeiro registro em estudos de eficiência portuária em 1993, conforme os artigos acima, tendo a aplicação intensificada depois de 2000. De forma genérica, os estudos tiveram foco diferente do aplicado neste trabalho, parte deles focalizam na técnica, medido a diferença entre especificar um modelo com retornos constantes ou variáveis de escala e utilizar fronteiras estocásticas, outros se preocupam em medir a eficiência comparando diferentes portos e não ganhos em eficiência intertemporal decorrentes de mudanças na estrutura de funcionamento da operação portuária com novos. A inovação aqui surge com a utilização do método DEA para compreender quais os impactos de mudanças institucionais no funcionamento do setor de transporte marítimo, particularmente na eficiência portuária.

\section{O SISTEMA PORTUÁRIO BRASILEIRO}

Esta seção resgata, brevemente, o histórico do setor portuário brasileiro antes e depois do processo de desestatização inicializado com o PND e as nuances sobre a sua infraestrutura.

\subsection{Visão geral dos portos brasileiros até 1990}

A configuração do sistema portuário brasileiro evoluiu ao longo do tempo em função do grau de intervenção estatal adotada. Segundo Brasileiro et al. (2001), na Era Vargas, foi definida uma hierarquia dos portos em grandes e pequenos, efetuada a reforma da legislação do setor e realizada diversas obras que abrangeram todos os portos brasileiros à época, gerando um aumento na movimentação de cargas e na arrecadação portuária. Já, em 1975, foi editada a Lei 6.222 que extinguiu o Departamento Nacional de Portos e Vias Navegáveis (DNPVN) e criou a Empresa de Portos do Brasil S.A. (Portobrás), vinculada ao Ministério dos Transportes. A partir daquele ano, além da Portobrás e suas subsidiárias, também faziam parte do sistema portuário as concessionárias privadas e estaduais. Essa forma de gestão foi alterada em virtude da extinção da Portobrás em março de 1990. Esse fato conduziu a União à edição do Decreto 99.475, em agosto de 1990, para autorizar, à época, o Ministério da Infra-Estrutura a descentralizar às sociedades de economia mista subsidiárias da Portobrás em liquidação ou às unidades federadas, mediante convênio e pelo prazo de um ano, a administração dos portos, das hidrovias e das eclusas elencados naquele decreto. Após essas alterações institucionais, passaram a existir portos administrados por companhias docas controladas pela União, por Estados e Municípios e por empresas privadas.

Diante desse contexto, a partir do início da década de 1990, iniciou-se uma reformulação do setor tendo como partida a extinção da Portobrás, processo que teve seguimento com a edição da Lei 8.630/1993, denominada de Lei de Modernização dos Portos.

\subsection{Portos brasileiros após 1990}

A promulgação da Lei de Modernização dos Portos abriu as portas ao setor privado às atividades de administração e operação portuária e propiciou as condições necessárias para um novo contexto operacional que pudesse contribuir para solucionar os problemas de falta de investimento, excesso de mão-de-obra, ausência de concorrência e elevados custos operacionais, os quais caracterizavam os portos brasileiros (Azeredo, 2004). A Lei 8.630/1993 apresentou quatro possibilidades para exploração do porto e das operações portuárias: (a) concessão do porto organizado; (b) qualificação do operador portuário; (c) arrendamento de instalação portuária; e (d) autorização de instalação portuária pública de pequeno porte, de estação de transbordo de cargas ou de terminal de uso privativo.

A Lei 8.630/1993, portanto, incentivou a competição e a parceria público-privado por meio do aumento dos investimentos e de gestão empresarial na operação portuária, de modo a proporcionar ganhos de produtividade e redução de tarifas, consoante Pêgo Filho et al. (1999). Essa melhoria pode estar associada à evolução tecnológica observada no setor portuário brasileiro tanto em termos de novos equipamentos e mão-de-obra especializada quanto de especialização de cargas, em especial, de acordo com Pires e Piccini (1999), com a utilização de contêineres.

A União também passou a delegar a administração e exploração dos portos para Estados e Municípios, com base na Lei 9.277/1996, podendo aqueles outorgar a exploração à iniciativa privada. Assim sendo, os portos brasileiros, em termos de regime de administração, podem ser configurados como concessão a governo estadual, delegação a governo estadual ou municipal, autorização a governo estadual, empresas vinculadas à SEP/PR e concessão à iniciativa privada, consoante representado na Tabela 1.

Outras modificações institucionais foram implementadas por meio da Lei 10.233/2001, que instituiu o Conselho Nacional de Integração de Políticas de Transportes (Conit), a Agência Nacional de Transportes Aquaviários (Antaq) e o Departamento Nacional de Infra-estrutura de Transportes (Dnit). A última alteração institucional se deu com a edição da Lei 11.518/2007, ao criar a SEP/PR. Por fim, em termos de alterações operacionais, foi editado o Decreto $6.620 / 2008$, que dispõe sobre políticas e diretrizes para o desenvolvimento e o fomento do setor de portos e terminais portuários de competência da SEP/PR, bem como disciplina a concessão de portos, o arrendamento e a autorização de instalações portuárias marítimas.

\subsection{A infraestrutura do sistema portuário}

A configuração do sistema portuário brasileiro parece complexa em virtude de seus distintos atores. Essa complexidade se estende para o desenho da infraestrutura portuária, que pode ser classificada em três estruturas: aquaviária, portuária e dos terminais portuários. Assim sendo, a efici- 
Tabela 1. Tipo e regime de administração dos principais portos brasileiros

\begin{tabular}{lll}
\hline Tipo & Regime & Portos \\
\hline \multirow{yy}{*}{ Pública } & Concessão a governo estadual & São Francisco do Sul-SC e São Sebastião-SP \\
\cline { 2 - 3 } & Delegação a governo estadual & $\begin{array}{l}\text { Cáceres-MT, Itaqui-MA, Macapá (Santana)-AP, Manaus-AM, Paranaguá e } \\
\text { Antonina-PR, Pelotas-RS, Porto Alegre-RS, Rio Grande-RS, Cachoeira do Sul-RS } \\
\text { Porto Velho-RO e Recife-PE }\end{array}$ \\
\cline { 2 - 3 } & Delegação a governo municipal & Corumbá-MT, Forno-RJ e Itajaí-SC \\
\cline { 2 - 3 } & Autorização a governo estadual & Suape-PE \\
\cline { 2 - 3 } & Empresas vinculadas à & Angra dos Reis-RJ, Aratu-BA, Areia Branca-RN, Barra do Riacho-ES, Belém-PA, \\
& SEP/PR ou ao Ministério dos & Cabedelo-PB, Charqueadas-RS, Estrela-RS, Fortaleza-CE, Ilhéus-BA, Maceió-AL, \\
& Transportes & Santarém-PA, Itaguaí(Sepetiba)-RJ, Vila do Conde-PA e Vitória-ES \\
\hline Privada & Concessão à iniciativa privada & Imbituba-SC, Panorama-SP e Presidente Epitácio-SP \\
\hline
\end{tabular}

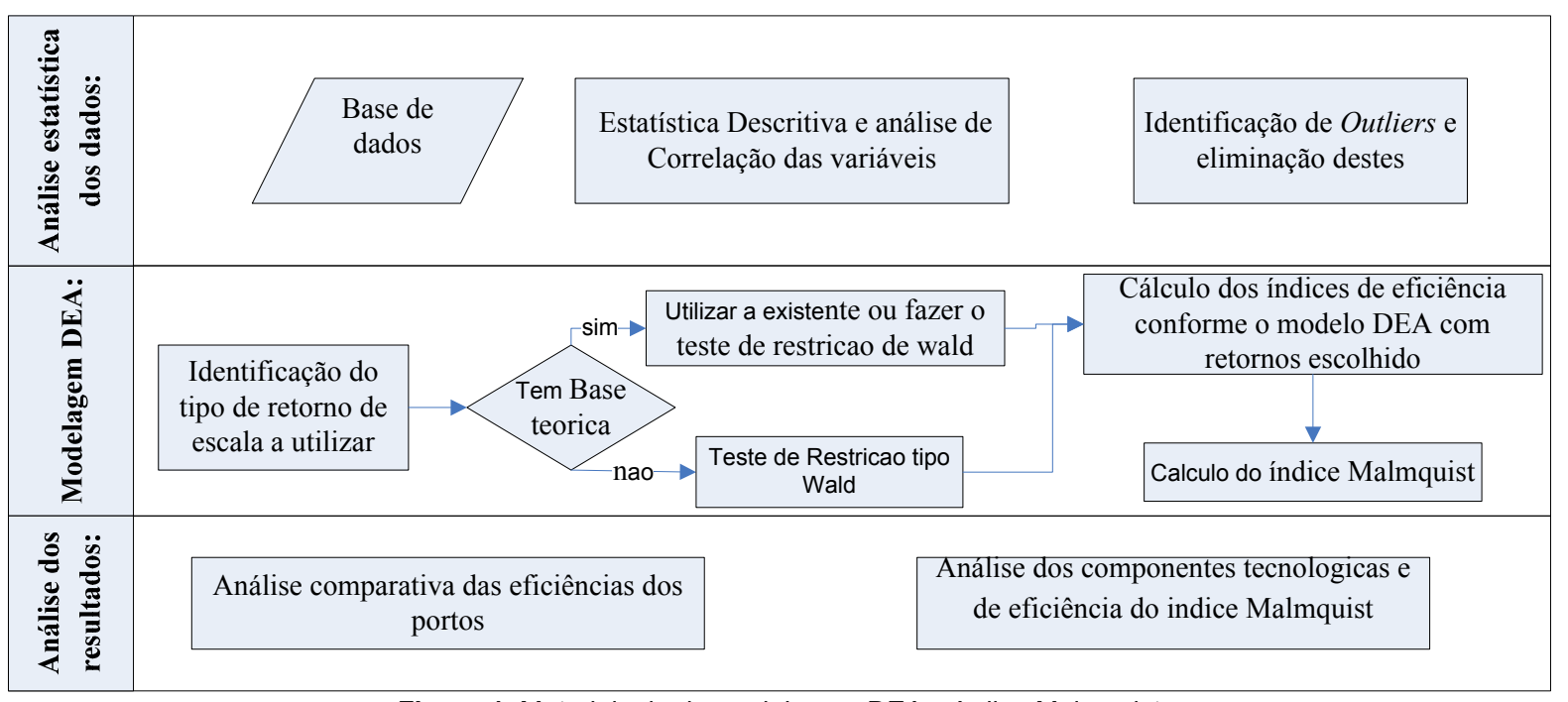

Figura 1. Metodologia de modelagem DEA e índice Malmquist

ência operacional do sistema depende das condições mínimas de cada uma dessas estruturas, de maneira conjunta, apesar de serem gerenciadas por atores diferentes.

Importa registrar que as modificações inseridas pela Lei 8.630/1993 apontam para o afastamento da autoridade portuária da operação, mas não da gestão do porto organizado. A compreensão desse aspecto é essencial para o presente artigo, porque tanto o poder público quanto a iniciativa privada investem no setor portuário. Nesse sentido, a eficiência produtiva dos portos brasileiros depende da interação desses investimentos, efetivados em locais apropriados, em função da infraestrutura portuária, e definidos em lei e nos contratos de arrendamento celebrados entre a autoridade portuária e a iniciativa privada, em decorrência das atribuições de cada um desses agentes.

A infraestrutura aquaviária é composta pela via navegável de acesso ao porto e é financiada exclusivamente por meio de recursos provenientes do Orçamento Geral da União $(\mathrm{OGU})$ e da cobrança por parte da autoridade portuária de tarifas destinadas a manter a profundidade, largura, sinalização náutica e área de fundeio em condições de atender às embarcações. A infraestrutura portuária também tem como fonte de recursos as tarifas portuárias cobradas pela autoridade portuária, além de recursos do OGU, com o intuito de garantir, principalmente, a segurança na atracação de embarcações e na movimentação de cargas.

A infraestrutura e superestrutura dos terminais portuários arrendados, por seu turno, são financiadas exclusivamente por recursos privados decorrentes de capital próprio e de terceiros, que foram a estrutura de capital dos arrendatários.
A cobertura desses recursos, dessa forma pode ser efetivada via financiamento e/ou cobrança pelos arrendatários pelos serviços prestados aos usuários de movimentação e armazenagem de cargas. Esses recursos podem ser aplicados, entre outras coisas, na aquisição de máquinas e equipamentos para movimentação de cargas e na construção, restauração, reforma e ampliação de pátios, armazéns e silos para armazenagem de cargas.

Assim sendo, a eficiência produtiva dos portos brasileiros está intimamente vinculada e de forma conjunta aos investimentos públicos efetivados pela autoridade portuária em infraestrutura aquaviária e portuária e aos investimentos privados realizados pelos arrendatários em infraestrutura e superestrutura dos terminais portuários arrendados.

\section{METODOLOGIA, APLICAÇÃO E RESULTADOS}

A metodologia adotada possui duas etapas, consoante a Figura 1. Segue a proposta de Araújo et al. (2008), com alterações na escolha do tipo de retornos e utilização de teste estatístico com uma função Cobb-Douglas. Além disso, aplica o índice Malmquist para a análise intertemporal.

\subsection{Etapa A}

\subsubsection{Base de dados}

A base de dados foi montada com informações da Agência Nacional de Transportes Aquaviários (ANTAQ) e da Empresa Brasileira de Planejamento de Transportes (GEIPOT) e constitui de um painel de dois anos (1999-2000), com da- 
Tabela 2. Estatística, média e desvio padrão e teste de normalidade, de insumos e produto para 1999 e 2000

\begin{tabular}{|c|c|c|c|c|c|c|c|c|c|c|c|c|}
\hline \multicolumn{13}{|c|}{ Insumos - infraestrutura aquaviária e portuária } \\
\hline & \multicolumn{2}{|c|}{$\begin{array}{l}\text { Bacia de evolução } \\
\text { largura }(\mathrm{m})\end{array}$} & \multicolumn{2}{|c|}{$\begin{array}{l}\text { Bacia de evolução } \\
\text { profundidade (m) }\end{array}$} & \multicolumn{2}{|c|}{$\begin{array}{l}\text { Canal de acesso } \\
\text { largura }(m)\end{array}$} & \multicolumn{2}{|c|}{$\begin{array}{l}\text { Canal de acesso } \\
\text { profundidade (m) }\end{array}$} & \multicolumn{2}{|c|}{$\begin{array}{l}\text { Cais acostável } \\
\text { comprimento }(m)\end{array}$} & \multicolumn{2}{|c|}{$\begin{array}{l}\text { Cais acostável } \\
\text { profundidade (m) }\end{array}$} \\
\hline & 1999 & 2000 & 1999 & 2000 & 1999 & 2000 & 1999 & 2000 & 1999 & 2000 & 1999 & 2000 \\
\hline$\mu$ & 606,81 & 643,42 & 12,60 & 13,92 & 467,98 & 468,45 & 13,48 & 14,16 & 2438,42 & 2438,42 & 10,64 & 10,63 \\
\hline$\sigma$ & 496,88 & 509,00 & 6,26 & 9,48 & 634,61 & 634,37 & 8,64 & 8,85 & 3071,88 & 3071,88 & 8,15 & 7,79 \\
\hline $\mathrm{P}$ & 0,0473 & 0,0473 & 0,0005 & 0,00001 & 0,0143 & 0,0071 & 0,0073 & 0,1039 & 0,0005 & 0,0005 & 0,000 & 0,000 \\
\hline
\end{tabular}

\begin{tabular}{c|ll|ll|ll|ll}
\hline \multicolumn{9}{c}{ Produtos } \\
\hline
\end{tabular}

TEU = Twenty-Foot Equivalent Unit - unidade equivalente a um contêiner padrão de dimensões de 20 pés por 8 pés por 8 pés, que perfazem cerca de $39 \mathrm{~m}^{3} ; \mathrm{un}=$ unidade; $\mathrm{t}=$ tonelada; $\mu$ : Média; $\sigma$ : Desvio padrão; $\mathrm{P}=$ probabilidade normal

dos de insumo e produto (ver Tabela 3) para os seguintes portos: Belém (PA); Cabedelo (PB); Fortaleza (CE); Ilhéus (BA); Imbituba (SC); Itajaí (SC); Itaqui (MA); Maceió (AL); Manaus (AM); Natal (RN); Paranaguá (PR); Porto Alegre (RS); Recife (PE); Rio de Janeiro (RJ); Rio Grande (RS); Salvador (BA); Santarém (PA); Santos (SP); São Francisco do Sul (SC); São Sebastião (SP); e Vitória (ES). Desses portos, têm-se informações sobre largura e profundidade de canais de acesso e bacias de navegação que constituem a infraestrutura aquaviária e sobre largura e comprimento de cais de atracação que compõem a infraestrutura portuária, todas adotadas como insumos para a produção. Além disso, obtiveram-se dados sobre a quantidade de contêineres e de carga geral movimentados, utilizados como produtos. O conjunto de informações alcança 598 observações, considerando insumos e produtos dos portos, tenso sido excluídos os dados sobre área de pátios por faltar informação de 4 portos. As DMUs foram consideradas como sendo portos fluviais ou marítimos. Das variáveis de insumo, obtiveram-se dados de ordem quantitativa e qualitativa (ex: quantidade de guindastes e potência dos guindastes), e com unidades de medida as mais variadas (ex: calado em metros e potência dos tratores em cavalo-vapor). Ainda, existem informações dos insumos em quantidade e faixas de potência operacional, os relativos a faixas serão eliminados por questão de precisão da análise. Os dados de produto são em contêineres (unidades: TEU e peso (t)) e carga geral (toneladas). O porto de Itaqui (MA) não movimenta contêiner e será excluído quando da análise da produção do porto sobre esse produto.

\subsubsection{Estatística descritiva e análise de correlação entre as variáveis}

Neste item, apresentam-se, descrevem-se e analisam-se as variáveis, bem como a proposta de agregação dos dados para a modelagem, tendo em vista que o objetivo da análise é a obtenção de um índice de eficiência técnica e não encontrar as ineficiências dos portos. Cumpre registrar, neste ponto, que o resultado da análise estatística sobre os dados dos insumos referentes à infraestrutura e superestrutura de instalações portuárias, especificamente, autoguindaste, guindaste pórtico, almoxarifados, armazéns internos, externos e frigoríficos, pátio, empilhadeira, balança, esteira, ca- minhão, carreta, caçamba e trator não apresentaram variação entre 1999 e 2000, decorrente, talvez, ou de falta de dados, de desativação ou ativação de novos equipamentos. Por sua vez, o insumo tanque de combustível, mensurado em unidades, registrou um ligeiro aumento, na medida em que a média em 1999 foi de 32,57 com desvio padrão de 61,28 e em 2000 a média passou para 34,2 com desvio padrão de 62,4 . Também foi constatado um pequeno aumento para o insumo silo para cereal, medido e unidades, pois a média passou de 5,9 com desvio padrão de 9,12, em 1999, para 6,2 com desvio padrão de 9,25, em 2000.

No que concerne aos insumos relativos à infraestrutura aquaviária e portuária e produtos referentes a 1999 e 2000 , o resultado da análise estatística consta da Tabela 2 e indicam que desvios padrões menores. Isso implica maior homogeneidade entre os portos, que pode estar associada ao fato de que essa infraestrutura depende de investimentos públicos decorrentes do orçamento geral da União. De uma forma geral, em que pese a irrelevante redução da profundidade do cais acostável, nota-se que houve benefícios no acesso de navios aos portos analisados, especificamente quanto ao aumento da largura e profundidade do canal de acesso e da bacia de evolução, o que pode ter gerado repercussão sobre a produção dos portos.

A Tabela 2 mostra, também, que os resultados sobre a movimentação de contêineres e carga geral (produtos) apresentam aumento na média de 1999 para 2000 com desvios padrões enormes e, portanto, possivelmente ter-se-á outliers. Ainda, todo o conjunto de observações foi submetido ao teste Jarque-Bera para normalidade, sendo o resultado obtido não tendo indício de inconsistência, conforme se observa da Tabela 2, haja vista que os p-valores (Prob.) não apresentaram significância, ou seja, não possuindo distribuição normal. Caso tivesse sido verificada normalidade, caberia excluir os valores extremos situados nas caudas da distribuição normal.

Para reduzir o trabalho computacional e entendendo que à infraestrutura e superestrutura das instalações portuárias é alocada mão de obra e investido capital, e que para a infraestrutura aquaviária e portuária também é investido capital, decidiu-se, com base no conceito econômico inerente a funções de produção, por agregar máquinas, equipamentos, silos e armazéns em unidade e as áreas comuns para poder 
tratá-las como proxies de trabalho e capital. Além disso, a escolha do tipo de modelo DEA com retornos de escala será mais bem entendida com o uso de apenas dois insumos agregados. Tem-se, ainda, que ao agregar os dados não haverá perda na análise, pois o interesse é na eficiência técnica e não na análise dos insumos e suas melhorias para alcançar melhor eficiência. Do ponto de vista matemático, restringir as observações a índices agregados não prejudicará o trabalho, pois o índice é uma combinação linear das variáveis observadas. Mas, no tocante ao trabalho, uma maior precisão requer a multiplicação da quantidade de pessoas alocadas em cada porto pelas horas trabalhadas ou ponderar pela potência dos equipamentos. Contudo, tendo em vista que não se obteve essa informação, considerou-se a soma da quantidade de equipamentos como proxy no modelo. Além disso, os portos têm diferentes administrações e horários de funcionamento que oscilam no ano e são de difícil replicação em um modelo. Como se trata de uma modelagem, o interesse é em replicar um efeito que é a eficiência técnica e presume-se representada pelos insumos utilizados.

No que diz respeito ao capital, as áreas utilizadas foram adotadas como proxies de capital estocado, tendo em vista que retrata, em certo grau, a quantidade de capital existente no porto. Isso se deve em virtude de não estar disponível o valor de capital associado a cada porto. Portanto, torna-se razoável supor, aventado na teoria econômica, que a média das áreas em relação ao total de equipamentos pode ser adotada como proxy de capital. Efetuada a agregação dos dados, analisou-se a correlação entre insumos e produtos agregados para 1999 e 2000.

O resultado referente a 1999 e 2000, para trabalho e capital, foi de 0,19 e 0,25, respectivamente, o que indica uma correlação baixa entre os insumos e desejada, visto que são variáveis explicativas da eficiência. Por outro lado, a correlação entre as produções de contêineres variou entre $0,98 \mathrm{e}$ 0,99 em 1999 e superou 0,99 em 2000, sendo valores bem altos e também esperados, pois refletem a combinação linear entre eles. Já a correlação entre contêineres e carga geral variou entre 0,69 e 0,72, em 1999, considerados valores medianos, enquanto que em 2000 variou entre 0,29 e 0,33 , valores baixos. Essa diferença nos resultados aponta para uma possível distinção nas operações portuárias realizadas nos portos. Assim, quando da modelagem, utilizar-se-á as variáveis de insumos para explicar qualquer produção via contêiner em unidade ou carga geral ou a combinação de insumos para a combinação de produtos. Neste ponto surge um questionamento, que é por que não utilizar uma combinação entre os contêineres da forma feita para o capital. Isso se deve ao fato de que essas combinações são de naturezas distintas, de modo que o contêiner é um unitizador de carga e, portanto, cada unidade de contêiner é um agregador per si.

\subsubsection{Identificação de outlier}

Os outliers foram identificados tomando a média e somando a um desvio padrão para o caso agregado e, sequencialmente, retirando os valores de produção que ultrapassaram esse limite. Assim, no ano de 1999, dezenove portos foram identificados como DMUs uniformes, enquanto o porto de Santos (SP) e de Itaqui (MA) foram caracterizados como outliers. Já no ano de 2000, a quantidade de portos foi reduzida para dezesseis DMUs uniformes, sendo os portos de
Paranaguá (PR), Rio Grande (RS) e Rio de Janeiro (RJ) caracterizados como outliers.

\subsection{Etapa B}

Nesta etapa será utilizado um teste paramétrico para verificar o tipo de retorno de escala. Tratar-se-á de verificar se o retorno é constante ou variado, pelo somatório das elasticidades de substituição técnica entre os insumos.

\subsubsection{Identificação do tipo de retorno de escala a utilizar}

A identificação do tipo de retorno refletirá sobre o tipo de modelo DEA a ser adotado, estando associado parametricamente a um modelo econométrico tipo Cobb-Douglas para cada ano, conforme Equação 4.

$$
Y_{t}=A k^{\alpha} L^{\beta}=>\ln (Y)=\ln (A)+\alpha \ln (K)+\beta \ln (L)
$$

O teste de restrição de Wald, conforme explicitado por Pindyck e Rubinfeld (2004), foi aplicado sobre as observações da amostra resultante após a exclusão de outliers, a fim de verificar se a soma das elasticidades é unitária (retornos constantes) ou diferente (retornos variados). O resultado, considerando 15 e 11 graus de liberdade, respectivamente para 1999 e 2000, e nível de significância de 10\%, apontou que o modelo para produção de contêineres para 1999 tem retornos constantes, enquanto que o para 2000 não tem retornos constantes, mas optou-se por manter os retornos constantes, dado a perda de informação dos portos para o segundo período. Quanto aos dados de carga geral, o resultado mostra que os retornos de escala são constantes para 1999 e 2000.

\subsubsection{Cálculo dos índices de eficiência conforme o modelo DEA e Índice Malmquist}

O cálculo da eficiência relativa dos portos foi efetuado conforme os modelos descritos na subseção anterior. Não se fará modelos orientados a produtos, pois o interesse é de termos uma medida da eficiência em relação à fronteira. Os resultados são apresentados com o índice Malmquist alcançando, assim, a última etapa da metodologia, conforme expresso na Tabela 3.

No geral, a Tabela 3, indica um crescimento na eficiência dos portos brasileiros com algumas ressalvas. Em relação à movimentação de contêineres, dos 14 portos analisados 5 registraram aumento de eficiência, 7 mantiveram o mesmo patamar e apenas Cabedelo (PB) e Vitória (ES), possivelmente por causa da concorrência de outros portos pertencentes a suas áreas de influência (hiterlândia), tiveram redução. Quanto à movimentação de carga geral, 11 portos aumentaram o nível de eficiência e três o mantiveram estável. O transporte de carga geral é o que registrou maior modificação. Observa-se que a variância tecnológica não ocorreu, o que era esperado pelo fato dos dados serem de dois anos sequenciais. Vê-se disso que os ganhos são decorrentes de aprendizagem e re-organização dos portos. É possível ainda que haja capacidade instalada ociosa no período anterior ou uma combinação desses fatores, mas qual deles é relevante foge ao escopo do trabalho e exigiria dados minuciosos das movimentações dos portos. Ainda, tendo em vista que os ganhos marginais para o transporte de contêineres e acentuados para a carga geral, infere-se que o setor não apresenta uniformidade na movimentação de cargas. Podem-se vislumbrar também quais são os portos especializados em carga geral e no transporte de contêineres, 
Tabela 3. Resultado dos Modelos DEA (BCC para eficiência técnica com retornos constantes e CCR com retornos variados)

\begin{tabular}{|c|c|c|c|c|c|c|c|c|c|c|c|}
\hline \multirow[b]{3}{*}{ Portos (UF) } & \multirow[b]{3}{*}{ Gestão } & \multicolumn{5}{|c|}{ Contêineres } & \multicolumn{5}{|c|}{ Carga Geral } \\
\hline & & \multicolumn{2}{|c|}{ Eficiência } & \multirow[t]{2}{*}{$V E$} & \multirow[t]{2}{*}{$V T$} & \multirow[t]{2}{*}{$I M$} & \multicolumn{2}{|c|}{ Eficiência } & \multirow[t]{2}{*}{$V E$} & \multirow[t]{2}{*}{$V T$} & \multirow[t]{2}{*}{$I M$} \\
\hline & & 1999 & 2000 & & & & 1999 & 2000 & & & \\
\hline Belém (PA) & Fed & 1,00 & 1,00 & 1,00 & 1,00 & 1,00 & 1,00 & 1,00 & 1,00 & 1,00 & 1,00 \\
\hline Cabedelo (PB) & Fed & 0,96 & 0,94 & 0,98 & 1,00 & 0,98 & 0,12 & 0,12 & 0,99 & 1,00 & 0,99 \\
\hline Fortaleza (CE) & Fed & 0,87 & 1,00 & 1,15 & 1,00 & 1,15 & 0,31 & 0,36 & 1,15 & 1,00 & 1,15 \\
\hline Ilhéus (BA) & Fed & 0,41 & 0,41 & 1,00 & 1,00 & 1,00 & 0,05 & 0,08 & 1,63 & 1,00 & 1,63 \\
\hline Imbituba (SC) & Priv & 0,72 & - & - & - & - & 0,24 & - & - & - & - \\
\hline Itajaí (SC) & Mun & 0,84 & 0,89 & 1,06 & 1,00 & 1,06 & 0,08 & 0,09 & 1,25 & 1,00 & 1,25 \\
\hline Maceió (AL) & Fed & 1,00 & 1,00 & 1,00 & 1,00 & 1,00 & 0,91 & 0,98 & 1,08 & 1,00 & 1,08 \\
\hline Manaus (AM) & Est & 0,38 & 0,48 & 1,28 & 1,00 & 1,28 & 0,21 & 0,30 & 1,39 & 1,00 & 1,39 \\
\hline Natal (RN) & Fed & 1,00 & 1,00 & 1,00 & 1,00 & 1,00 & 1,00 & 1,00 & 1,00 & 1,00 & 1,00 \\
\hline Paranaguá (PR) & Est & 1,00 & - & - & - & - & 0,67 & - & - & - & - \\
\hline Porto Alegre (RS) & Est & 0,16 & 0,16 & 1,00 & 1,00 & 1,00 & 0,24 & 0,46 & 1,89 & 1,00 & 1,89 \\
\hline Recife (PE) & Fed & 0,66 & 0,67 & 1,00 & 1,00 & 1,00 & 0,16 & 0,18 & 1,10 & 1,00 & 1,10 \\
\hline Rio de Janeiro (RJ) & Fed & 1,00 & - & - & - & - & 0,28 & - & - & - & - \\
\hline Rio Grande (RS) & Est & 1,00 & - & - & - & - & 0,29 & - & - & - & - \\
\hline Salvador (BA) & Fed & 0,58 & 0,59 & 1,02 & 1,00 & 1,02 & 0,10 & 0,11 & 1,17 & 1,00 & 1,17 \\
\hline Santarém (PA) & Fed & 0,94 & 0,94 & 1,00 & 1,00 & 1,00 & 0,07 & 0,08 & 1,20 & 1,00 & 1,20 \\
\hline São Francisco da Sul (SC) & Est & 1,00 & 1,00 & 1,00 & 1,00 & 1,00 & 0,89 & 0,96 & 1,07 & 1,00 & 1,07 \\
\hline Vitória (ES) & Fed & 0,59 & 0,55 & 0,93 & 1,00 & 0,93 & 0,14 & 0,17 & 1,28 & 1,00 & 1,28 \\
\hline
\end{tabular}

contudo, com ressalvas para a capacidade produtiva de cada porto. Infelizmente, não foi possível analisar alguns portos relevantes por falta de informação ou mudança de nível de produção no período 1999-2000 que os situou fora das faixas de corte estabelecidas.

Em termos de regime de administração dos 14 portos abrangidos, o resultado da Tabela 3 , grosso modo, aponta para o fato de que: (a) dos 10 portos sob a gestão de docas federais vinculadas à SEP/PR, no caso de movimentação de contêineres, dois registraram aumento e dois redução da eficiência, enquanto seis não apresentaram alteração, e no caso de carga geral, sete aumentaram a eficiência e três mantiveram o mesmo nível em ambos os exercícios avaliados; (b) o único porto sob a gestão municipal aumentou o nível de eficiência tanto na movimentação de contêineres quanto na de carga geral; e (c) dos três portos sob a gestão estadual, no caso de movimentação de contêineres, um aumentou o nível de eficiência e dois registraram redução, e no caso de carga geral todos tiveram aumento de eficiência. Cumpre registrar, no entanto, que somente os portos de Belém (PA) e Natal $(\mathrm{RN})$, sob gestão federal, atingiram a fronteira de produção em ambos os exercícios para ambos os produtos. Os portos de Maceió (AL) e São Francisco do Sul (SC), sob gestão federal e estadual, respectivamente, também atingiram a fronteira de produção em ambos os exercícios, porém, somente relativa à movimentação de contêineres. O porto de Fortaleza (CE), sob gestão federal, por seu turno, alcançou a fronteira de produção para a movimentação de contêineres referente ao ano de 2000.

Além disso, vale destacar o nível de eficiência dos demais portos, considerando os intervalos de valores como sendo alto, médio e baixo, respectivamente, $1>V E \geq 0,75$, $0,75>V E \geq 0,5$ e $V E<0,5$. Assim sendo, em termos de movimentação de contêineres, os portos de Cabedelo (PB), Itajaí (SC) e Santarém (PA) tiveram alto nível de eficiência, os portos de Recife (PE), Salvador (BA) e Vitória (ES) registraram grau médio de eficiência e os portos de Manaus (AM), Porto Alegre (RS) e Ilhéus (BA) apresentaram baixo nível de eficiência. Relativamente à movimentação de carga geral, os portos de Maceió (AL) e São Francisco do Sul
(SC) proporcionaram alto grau de eficiência, enquanto que os portos de Cabedelo (PB), Fortaleza (CE), Ilhéus (BA), Itajaí (SC), Manaus (AM), Porto Alegre (RS), Recife (PE), Salvador (BA), Santarém (PA) e Vitória (ES) registraram baixo nível de eficiência.

No que tange ao resultado indicado pelo índice Malmquist, no caso deste trabalho obtido exclusivamente em função da variância da eficiência, observa-se que para a movimentação de contêineres os portos de Fortaleza (CE), Itajaí (SC), Manaus (AM) e Salvador (BA) apresentaram ganhos intertemporais, enquanto que os portos de Cabedelo (PB) e Vitória (ES) registraram perdas. Para a movimentação de carga geral, os portos de Fortaleza (CE), Ilhéus (BA), Itajaí (SC), Maceió (AL), Manaus (AM), Porto Alegre (RS), Recife (PE), Salvador (BA), Santarém (PA), São Francisco do Sul (SC) e Vitória (ES) obtiveram ganhos intertemporais, enquanto que apenas o porto de Cabelo (PB) teve perdas.

\section{CONCLUSÕES}

A análise da eficiência produtiva de portos brasileiros realizada no presente estudo possui caráter preliminar e restrito às informações de insumos e produtos relativos ao biênio 1999-2000, especificamente sobre infraestrutura e superestrutura dos terminais portuários, infraestrutura aquaviária e infraestrutura portuária, alcançando um total de 598 observações referentes a 18 portos.

A metodologia desenvolvida apresenta um avanço em termos de análise envoltória de dados (DEA), tendo em vista a aplicação do teste de Wald para determinar ex ante, e não ad hoc, os retornos de escala do modelo construído. Dessa forma, a análise se tornou mais robusta e estatisticamente significante. Importa destacar, ainda, que o método DEA na forma aplicada permitiu construir uma fronteira de eficiência para 14 portos dentre os abordados e identificar aqueles que constituíram os vértices da fronteira, sendo considerados de maior eficiência operacional para a amostra avaliada.

O resultado em termos de variância da eficiência com 
base no modelo construído indicou crescimento na eficiência dos portos brasileiros no biênio 1999-2000, notoriamente para a movimentação de carga geral e de forma menos acentuada para a de contêineres. Identificaram-se, também, benefícios intertemporais em função do índice Malmquist, no caso deste trabalho exclusivamente por conta da variância da eficiência, haja vista a impossibilidade de se avaliar a variação tecnológica devido ao período restrito. Os benefícios intertemporais constatados, consideradas as informações analisadas, indicam que ocorreram, principalmente, em função da aplicação de recursos públicos, na medida em que estavam associados à melhoria da infraestrutura aquaviária e portuária dos portos.

Sugere-se um estudo mais aprofundado com ampliação das informações com mais variáveis e, se possível, desagregadas por portos, a fim de construir um painel de dados para vários exercícios, no mínimo cinco, de modo a permitir identificar a variação tecnológica. Ainda, recomenda-se utilizar outras modelagens como, por exemplo, método DEA com fatores aleatórios e fronteira estocástica para comparação de resultados.

\section{AGRADECIMENTOS}

O autor Francisco Gildemir Ferreira da Silva agradece a CAPES pelo apoio nesta pesquisa ao conferir bolsa de doutoramento no CAEN/UFC.

\section{REFERÊNCIAS BIBLIOGRÁFICAS}

Aigner, D. J.; C. A. K. Lovell e P. Schmidt (1977) Formulation and estimation of stochastic frontier production function models. Journal of Econometrics,v. 6, p. 21-37.

Araújo, C. E. F.; F. G. D. Martins e F. G. F. Silva (2008) Análise exploratória da eficiência operacional de empresas de transporte rodoviário interestadual de passageiros por ônibus no Brasil. Anais da XXII ANPET [CD-ROM]. Fortaleza, CE.

Azeredo, L. C. L. (2004) Investimento em infra-estrutura no Plano Plurianual (PPA) 2004-2007 - uma visão geral. Texto para Discussão n. 1024. Brasília: IPEA.

Belloni, J. A. (2000) Uma Metodologia de Avaliação da Eficiência Produtiva de Universidades Federais Brasileiras. Tese (Doutorado), Programa de Pós-Graduação em Engenharia de Produção, Universidade Federal de Santa Catarina, UFSC. Florianópolis.

Brasileiro, A.; E. M. Santos; J. J. G. Aragão; J. M. Senna; O. Lima Neto e R. D. Orrico Filho (2001) Transporte no Brasil: história e reflexões. Brasília: Ed. Universitária da UFPE, GEIPOT.

Castro, N. e P. Lamy (1992) A desregulamentação do setor transportes: o caso do subsetor portuário. Texto para Discussão n. 28. IPEA/DIPES.

Charnes, A.; W. W. Cooper; A. Y. Levin e L. Seiford (1994) Data envelopment analysis: theory, methodology and applications. USA: Kluwer Academic Publishers.

CNT (2006) Pesquisa aquaviária CNT 2006 - portos marítimos: longo curso e cabotagem. Confederação Nacional dos Transportes. Brasília.

Coelli, T.; D.S.P. Rao e G. E. Battese (1997) An introduction to efficiency and productivity analysis. USA: Kluwer Academic Publishers, 3rd printing.

Färe, R; S. Grosskopf e N. Norris (1994) Productivity growth, technical progress, and efficiency change in industrial countries. The American Economic Review, v.84, n.1, p. 66-82.

Farrell, M. J. (1957) The measurement of productive efficiency. Journal of the Royal Statistical Society, Series A, v. 120, p. 253-290.

Fontes, O. H. P. e J. C. C. B. S. Mello (2006) Avaliação da eficiência portuária através de uma modelagem DEA. Anais do IX SPOLM. Rio de Janeiro.

GEIPOT (1998) Financiamento do subsetor portuário. Empresa Brasileira de Planejamento de Transportes. Brasília.

GEIPOT (2001) A reforma portuária brasileira. Empresa Brasileira de Planejamento de Transportes. Brasília.
Gonçalez, M. M. e L Trujilo (2008) Efficiency measurement in port industry: a survey of the empirical evidence. Discussion paper series $\mathrm{n}$. 07/08. Department of Economics City, University of London.

Greene, W. H. (1990) A gamma-distributed stochastic frontier model. Journal of Econometrics, v. 46, p. 141-164.

Gujarati, D. N. (2000) Econometria básica. $3^{\mathrm{a}}$ ed. São Paulo: Makron Books.

Lima, E. e L. Velasco (1997) Marinha Mercante do Brasil: perspectivas do novo cenário mundial. Revista do BNDES, dez, p. 68.

Lin, L e L. Tseng (2005) Application of DEA and SFA on the measurement of operating efficiences for 27 international container ports. Proceedings of the Eastern Asia Society for Transportation Studies, v. 5, p. 592-607.

Malmquist, S. (1953) Index numbers and indifference surfaces. Trabajos de Estatistica, v. 4, p. 209-242.

Meeusen, W. e Van den Broeck (1977) Efficiency estimation from CobbDouglas function with composed error. International Economic Review, v. 18, p. 435-444.

Ministério dos Transportes (2001) Anuário estatístico portuário 2000: principais portos marítimos, fluviais e lacustres. Disponível em $<$ www.transportes.gov.br> (Acessado em 23/6/2009).

Pêgo Filho, B.; J. O. Cândido Júnior e F. Pereira (1999) Investimento $e$ financiamento da infra-estrutura no Brasil: 1990/2002. Texto para Discussão n. ${ }^{\circ}$ 680. Brasília: IPEA.

Pindyck, R. S. e D. L. Rubinfeld (2004) Econometria: modelos $e$ previsões. Rio de Janeiro: Elsevier.

Pires, J. C. L. e M. S. Piccini (1999) A regulação dos setores de infraestrutura no Brasil. BNDES.

Rios, L. R.; A. C. G. Maçada e J. L. Becker (2004) Medindo a eficiência das operações dos terminais de conteiners brasileiros. Anais do II $C G A C E$.

Souza Jr., J. J. N. C. (2007) Análise da eficiência dos portos da região nordeste do Brasil baseada em análise envoltória de dados. Monografia (graduação) Universidade Federal do Ceará.

Wang, T. F.; D. W. Song e K. Culliname (2002). The applicability of DEA to efficiency measurement of container ports. Disponível em: $<\mathrm{http}: / /$ www.eclac.cl $>$. 